\title{
Nondestructive Evaluation of Historic Hakka Rammed Earth Structures
}

\author{
Ruifeng Liang ${ }^{1, *}$, Gangarao Hota ${ }^{1}$, Ying $\operatorname{Lei}^{2}$, Yanhao Li ${ }^{2}$, Daniel Stanislawski ${ }^{1}$ and \\ Yongqiang Jiang ${ }^{2}$
}

1 Constructed Facilities Center, West Virginia University, Morgantown, WV 26506, USA;

E-Mails: ghota@mail.wvu.edu (G.H.); dstanisl@mix.wvu.edu (D.S.)

2 School of Architecture and Civil Engineering, Xiamen University, Xiamen 361005, Fujian, China;

E-Mails: ylei@xmu.edu.cn (Y.Lei.); lyhhyl@xmu.edu.cn (Y.Li.); gonel@qq.com (Y.J.)

* Author to whom correspondence should be addressed; E-Mail: rliang@mail.wvu.edu;

Tel.: +1-304-293-9348; Fax: +1-304-293-7109.

Received: 4 December 2012; in revised form: 10 December 2012 / Accepted: 11 January 2013 /

Published: 21 January 2013

\begin{abstract}
The in-service Hakka rammed earth buildings, in the Fujian Province of China, are unique in design and performance. Their UNESCO's inscription as World Heritage sites recognizes their artistic, cultural, social and historic significance. Sponsored by the National Science Foundation of the United States, the authors have examined the engineering values of these buildings in terms of comfortable living at low energy consumption, sustainability and durability. The objective of this study was to better understand the thermo-mechanical and aging responses of Hakka earth buildings under thermal and earthquake loads through nondestructive field evaluation, including full-scale roof truss and floor testing, laboratory testing of field samples and finite element modeling. This paper presents our observations and findings from the field nondestructive evaluations with emphasis on the integrity of the rammed earth outer walls and inner wood structures, as well as the thermal comfort of living in these buildings, while a second paper presents the results from the material characterization of field samples and the structural responses of a representative building under earthquake induced loads through finite element analysis.
\end{abstract}

Keywords: Hakka Tulou; rammed earth; earth structures; load test; thermal comfort; NDE; nondestructive evaluation; ultrasonic; rebound hammer; Infrared thermography 


\section{Introduction}

Rammed earth construction is a widespread, ancient technique where soil is taken from the ground and compacted between vertical wooden frameworks (molds), which are then removed, leaving an earth wall. Many historic rammed earth structures are either in service or abandoned, in many countries, e.g., China, India, Spain, Morocco, Yemen and Egypt [1]. Recently, rammed earth has been attracting significant interest again as a sustainable construction material because of its numerous benefits to the environment compared to concrete and steel [2]. For example, the Desert Living Center, outside Las Vegas, has been constructed from rammed earth and aims to provide Nevada residents with information on sustainable living [3].

Hakka rammed earth buildings (also known as Fujian Tulou), in the Fujian Province of China, reflect the emergence of innovation, evolution and advancement in the engineering of rammed earth construction from the 8th to 20th centuries. Figure 1 shows a typical Hakka village of Yongding County living in Tulou buildings, while Figure 2 is a geographic location map of Fujian Tulou in China. These earth buildings have thick ( $\sim 2 \mathrm{~m}$ ) outer rammed earth walls and inner wooden structures that make up floors and rooms; they are three to five stories in height and round or square in shape; there are hundreds of rooms in each building housing up to 800 people. Since the 1980 s, thousands of visitors (including professionals and scholars) have visited Hakka earth buildings, resulting in many illustrative photographs and travel logs about Tulou's characteristics and architectural features, including defense devices and fire walls. It is worth noting that Aaberg, a Danish architect, visited Hakka earth buildings in 1997 and reported the architectural marvel of those structures [4]. More recently, Ostrowski, a Canadian architect, has been researching the ecological footprint of Hakka earth buildings and discussed these buildings in terms of their planning, design, construction, lifestyle, resource management, renewable energy and modest ecological footprint [5]. However, people have underestimated the engineering values of these buildings in terms of low energy consumption for comfortable living, sustainability and durability [6].

Figure 1. Hakka Tulou Village, Chuxi Tulou Group, Yongding, Fujian, China.

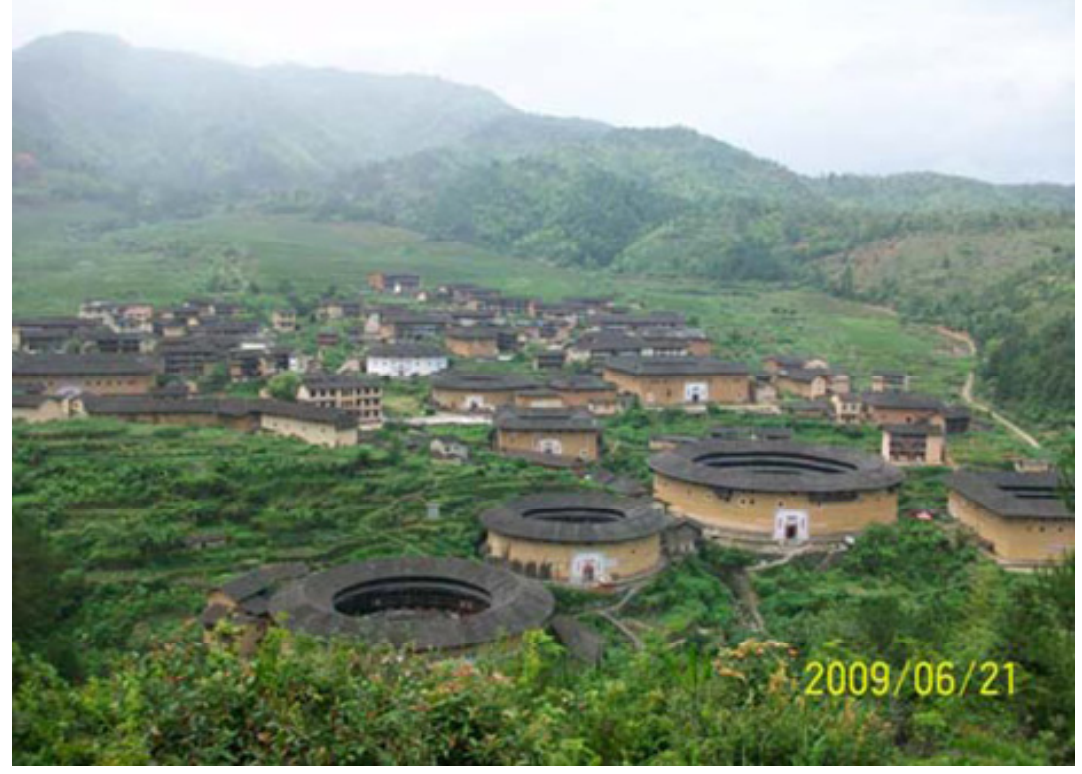


Figure 2. Location Map of Fujian Tulou in China.

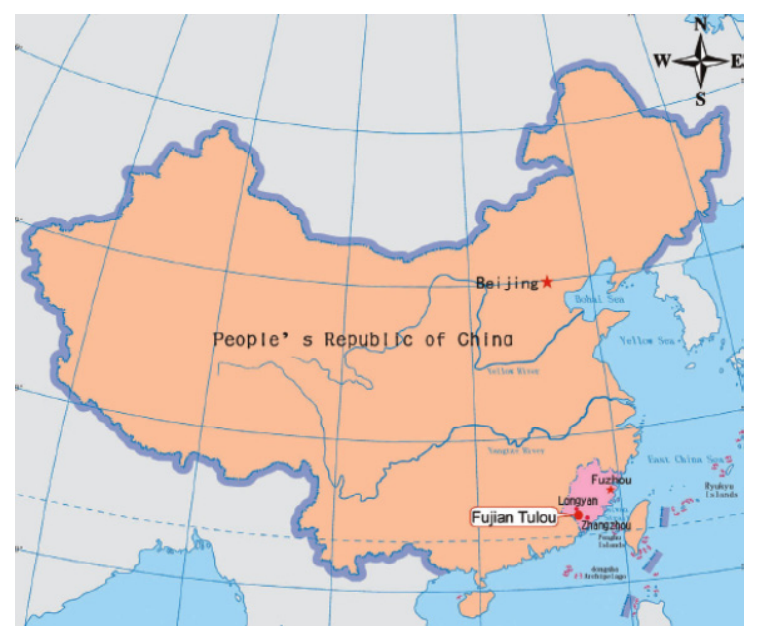

An international group of researchers traveled to Hakka villages in Yongding, Fujian from 15 June-15 July, 2009 and field-studied several representative Hakka earth buildings. A group photo of the research team with local Government Officials is shown in Figure 3. The team includes Professors Gangarao Hota and Ruifeng Liang from the Constructed Facilities Center of West Virginia University, Professor Ying Lei, Yanhao Li (Technician) and Yongqiang Jiang (Graduate Research Assistant) from the School of Architecture and Civil Engineering of Xiamen University, Jorg Ostrowski (Architect) from Autonomous \& Sustainable Housing Inc. of Canada and Minoru Ueda (Architect) from MU Design of Japan.

Figure 3. The research team standing in the front of Zhencheng Tulou, Hongkeng Village, Yongding, Fujian.

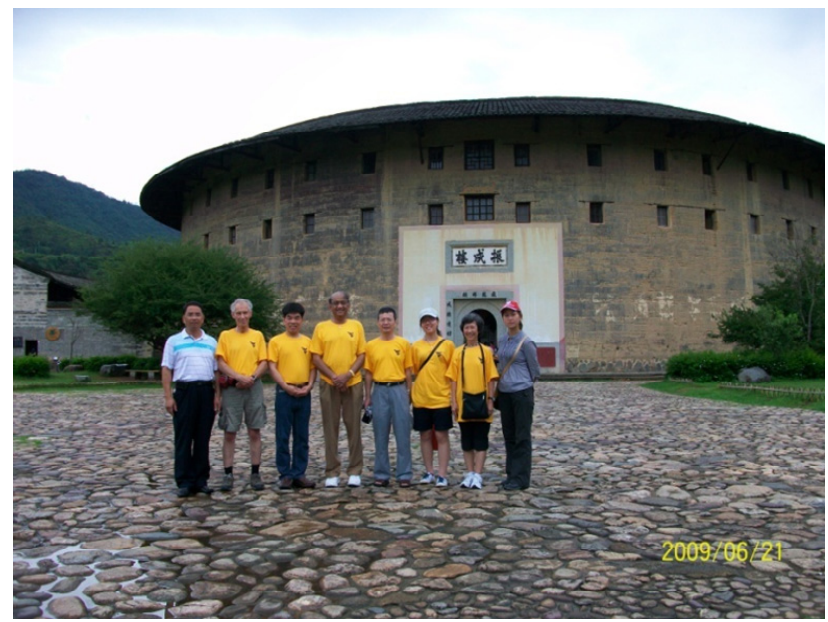

The Hakka earth buildings investigated are listed in Table 1. The scope of work included: (1) identification of the constituent materials in the rammed earth and investigation of the durability of the constituents; (2) investigation of the structural integrity of Hakka buildings under extreme loads, including potential modes of failure and verification (if any) of the reported self-healing of cracking; (3) analysis of the heat transfer process through a rammed earth wall for thermal comfort and energy-efficiency; and (4) evaluation of the potential benefits of the material in terms of embodied 
energy (consumed) and structural performance for potential implementation in modern constructions. All the field studies were conducted as nondestructive evaluations (NDE) using techniques and equipment, such as Infrared Thermography (IRT) Scanning Camera, Rebound Hammer, Ultrasonic Testing Device, strain data acquisition system and thermocouples. The data collected from the field were further processed at West Virginia University (WVU) and Xiamen University (XMU) for their implications along with the data generated through testing the field-collected samples at both WVU and XMU laboratories. This paper reports the strength data of rammed earth walls as determined from NDE, strain data of floor and roof truss beams from load tests and climate data.

Table 1. Hakka earth buildings studied.

\begin{tabular}{clccc}
\hline Title of Tulou & Shape & $\begin{array}{c}\text { Number of } \\
\text { Story }\end{array}$ & Age & Status \\
\hline Fuxing Tulou & Square & 2 story & over 1,200 years & partially in service \\
Wuyun Tulou & Square & 4 story & over 500 years & partially in service \\
Chengqi Tulou & Round & 4 story & over 300 years & in service \\
Huanji Tulou & Round & 4 story & over 300 years & in service \\
Zhencheng Tulou & Round & 4 story & about 100 years & in service \\
\hline
\end{tabular}

\section{Radiocarbon Dating Age of Chengqi Tulou}

To validate the ages of the Tulou buildings that were reported in the local official records, as a case study, a wooden sample from Chengqi Tulou was tested for its radiocarbon dating age. Chengqi Tulou was reportedly built from 1662-1709. This wooden sample was cut from a roof truss beam in the Chengqi Tulou and sent to the NSF-University of Arizona Accelerator Mass Spectrometry (AMS) Facility at the Department of Physics, University of Arizona, Tucson, AZ. The carbon dating measurement shows the sample at radiocarbon years $111+/-47$ BP. Radiocarbon dates require calibration in order to transform them into calendar age ranges. The calibration plot for the sample tested is provided by the NSF-Arizona AMS team and shown in Figure 4. The result indicates that there is a 95.4\% probability that the sample is aged between the two calendar age ranges $1675 \mathrm{AD}-1778 \mathrm{AD}$ and 1799 AD-1941 AD. This observation is consistent with the completion date of 1709 of Chengqi Tulou. Only the age of the wooden sample from Chengqi Tulou has been tested and verified, while the ages of all other Tulou buildings reported herein are collected from local government records.

\section{Nondestructive Evaluation of Rammed Earth Walls}

Nondestructive evaluation (NDE) techniques refer to those methods that enable the testing of materials/ structural components without impairing their future usefulness [7]. In this study, NDE testing was used in order to preliminarily assess the conditions of the rammed earth walls without damaging the historic structures. Both an ultrasonic testing device and rebound hammer were employed to field-evaluate the wall systems in a comparative manner. In addition, Infrared Thermography Scanning Camera was also used with the intention to detect the bonding status between earth and the wall rib. The findings using the above three NDE tools are presented in this section. In situ load tests of the roof truss and floor structure using a strain data acquisition system are discussed 
in the next Section, while temperature and humidity data collected using thermal couples and data loggers are discussed in Section 5.

Figure 4. Carbon dating age of Chengqi Tulou.

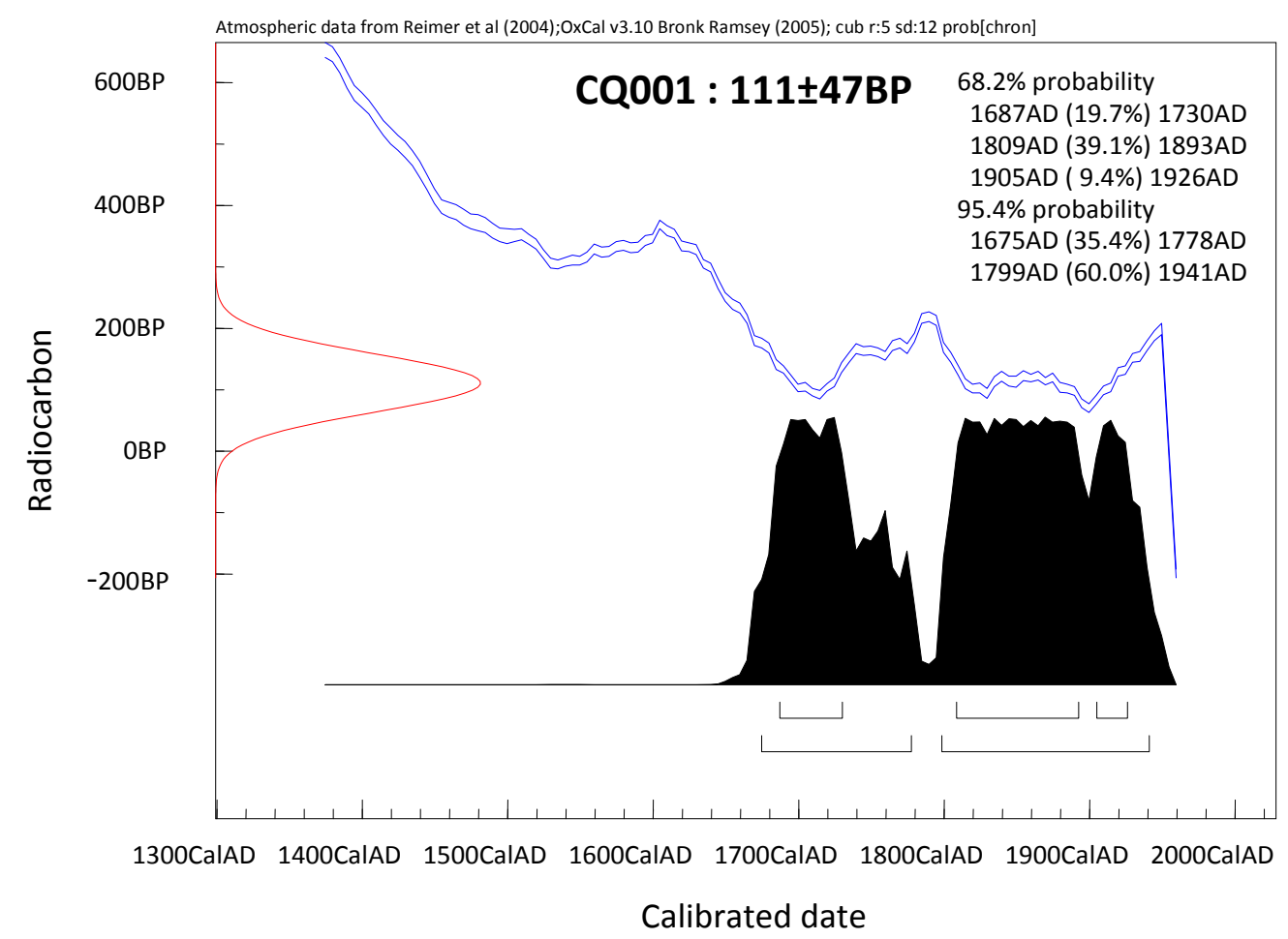

\subsection{Ultrasonic Method}

Ultrasonic testing is a NDE test, which can reflect the strength of the material and/or detect if defects are present in the material. In this test, a wave is produced by an ultrasonic transducer; the wave travels through a material, such as the rammed earth wall in this study, and then, the wave is detected by a receiver (as shown in Figure 5). The way in which the wave propagates can give information with respect to the integrity of the structure being tested. More specifically, the velocity of the wave is a function of the material's properties, such as stiffness, density and Poisson's ratio, as well as the presence of defects. Similarly, the amplitude of the wave transmitted through a more "sound" material or a material that shows fewer defects is expected to be higher. A combination of velocity and amplitude measurements increases the sensitivity of the ultrasonic technique to defects. In most cases, a decrease in wave amplitude represents a possible defect. It is useful to compare the trend of velocity data of a wave to that of the amplitude to see if there are inconsistencies. If inconsistencies exist, then there is a possibility that a defect may be present [7].

The model NM-4B ultrasonic device that was used in the study was developed and manufactured by Beijing Zhongkelujian Instrument \& Equipment Co., Ltd. This portable device can dynamically in real-time display the wave with automatic scaling of frequency and amplitude at high sensitivity. This device is designed to detect the strength or cracking depth of concrete or its uniformity or defects.

The ultrasonic tests were conducted on Zhencheng Tulou, Wuyun Tulou, Huanji Tulou and Fuxing Tulou. However, the data of Fuxing Tulou were invalid because all the measurements on Fuxing Tulou 
were conducted on the wet walls caused by rainy weather. Figure 6 shows both the ultrasonic velocity and amplitude results for the buildings tested. Note that each data point represents an average of 25 to 30 measurements. Both charts show a consistent trend. As can be seen in Figure 6, apparently, there is no direct correlation between the ages of the Tulou structures and the velocity/amplitude (the strength of the rammed earth walls) of the ultrasonic wave. Other than the age, there are many more parameters in the wall system varying from one building to another, including different earth constituents, with or without wall ribs and varying construction quality.

Figure 5. Ultrasonic testing heads and device.
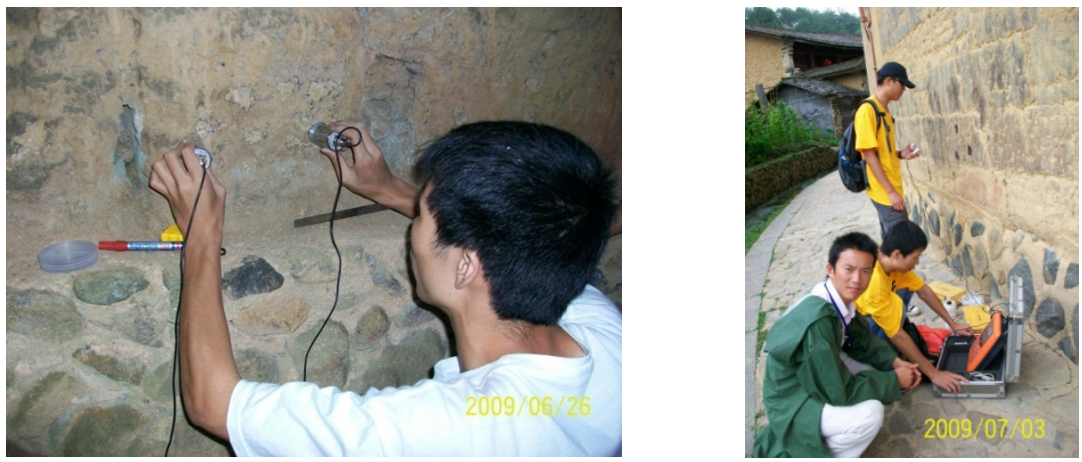

Even though there are limited ultrasonic data, a useful discussion can be made with reference to the compression properties of the rammed earth wall samples that were generated in the laboratory [8]. The compression strength and modulus data available for the buildings studied are also listed in Figure 6. Ultrasonic testing indicates that the Zhencheng earth wall is stronger than that of Wuyun. This observation agrees with the compression testing results. The ultrasonic result also shows that the Wuyun earth wall is stronger than that of Huanji. Unfortunately, the Huanji Tulou earth sample was too brittle and the researchers were not able to prepare any specimens of a regular shape. Thus, the Huanji Tulou earth sample would have the lowest strength among the buildings studied. The Fuxing Tulou earth sample has the highest compression strength and modulus, even though it was built 1,200 years ago. This is because its earth wall was made of a mix known as "sahetu" that contains a significant amount of lime [7]. Therefore, the limited ultrasonic testing results do appear to agree with the mechanical properties of the earth wall samples.

Figure 6. Ultrasonic testing results.
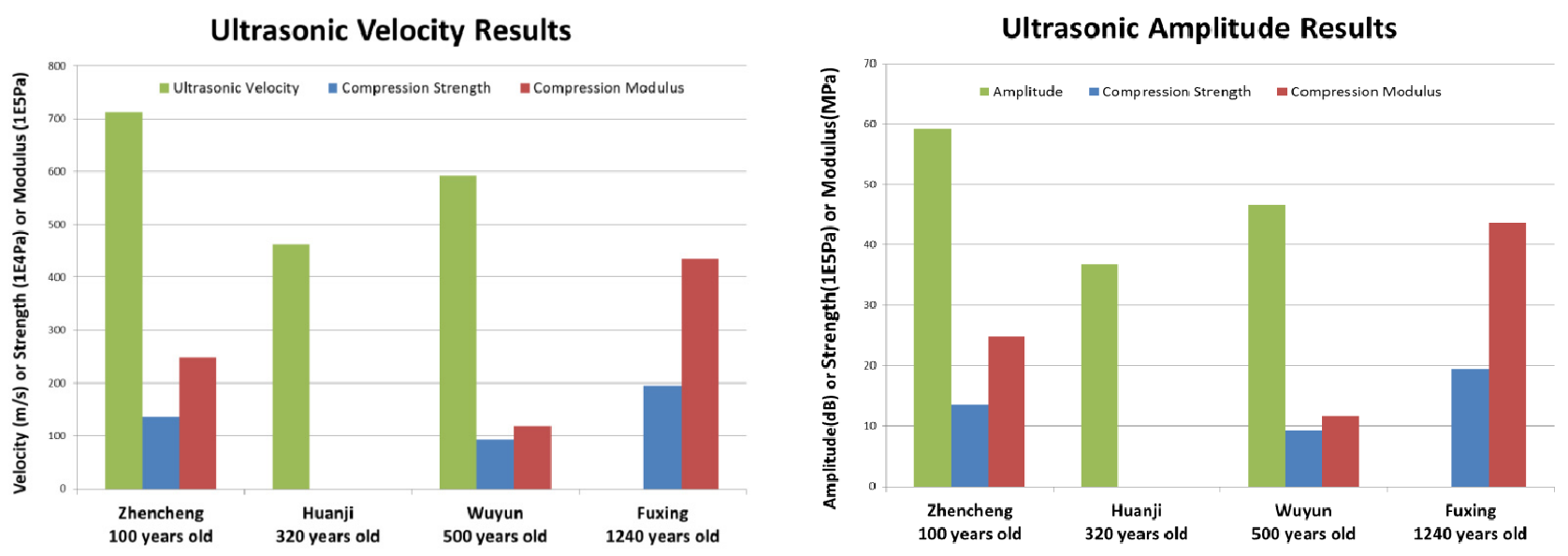


\subsection{Rebound Hammer Method}

As per ASTM C805, a rebound hammer works as follows: a steel hammer impacts, with a predetermined amount of energy, a steel plunger in contact with the surface of concrete, and the distance that the hammer rebounds is measured. This is shown in Figure 7 for the rammed earth wall instead of concrete. Note that the rebound hammer is not designated for a rammed earth wall, but it might offer a method to quantitatively evaluate the strength of Tulou earth walls. During the field study, two types of rebound hammer models, HT-75 and HT-20, were used, and both were manufactured by Tianjin Building Instrument \& Testing Machine Company. The model HT-75 applies an impact energy of $0.075 \mathrm{kgf}$.m and is designated for red brick applications, while the model HT-20 applies an impact energy of $0.020 \mathrm{kgf} . \mathrm{m}$ for mortar applications. Figure 8 shows the results of the rebound hammer tests using both HT-75 and HT-20. Each data point represents an average of 32 to 64 rebound hammer measurement readings. Again, all the measurements on the Fuxing building were conducted on wet walls because of rainy weather during the field study, and so the values were not representative.

Figure 7. Rebound hammer being used to test the rammed earth wall.

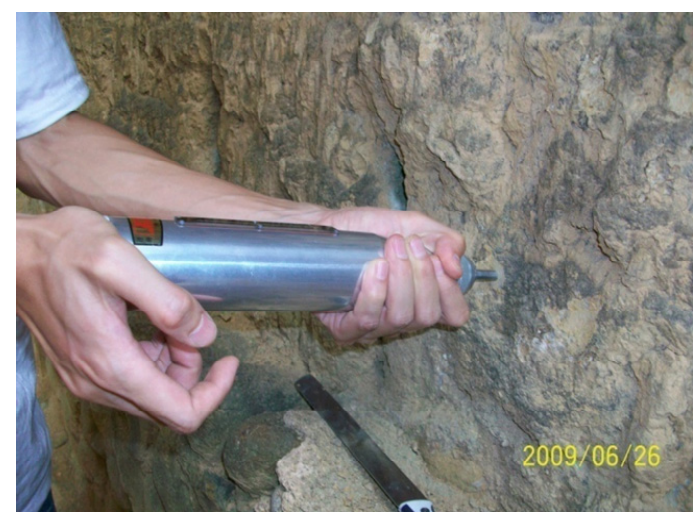

Similar to the ultrasonic data, the discussion on the rebound number can be drawn with reference to the strength data of the rammed earth wall samples reported in the paper by Liang et al [8]. As shown in Figure 8, apparently, the HT-75 brick rebound hammer readings correlated to the compression strength data of the earth walls better than the HT-20 mortar rebound hammer readings. It is interesting to note that the Wuyun and Huanji earth walls have had similar HT-75 hammer readings, and the HT-20 mortar rebound hammer average reading of the Huanji building earth wall was much higher than those of the Zhencheng and Wuyun buildings.

In this study, an ultrasonic device and rebound hammer were used with the intention of preliminarily comparing the strengths of the rammed earth walls of the different Tulou buildings tested. However, a calibration chart of the ultrasonic device/rebound hammer for the rammed earth wall should be developed in order to derive the earth wall strength values from such tests. Currently, a comparison of NDE data with experimentally determined strength data of the rammed earth walls would provide some trends for further use of such NDE techniques. The results indicate that ultrasonic testing appears to reflect the strength of the earth wall better than the rebound hammer. The nature of 
rammed earth wall is more like red brick than mortar; hence the HT-75 rebound hammer instead of HT-20 should be used.

Figure 8. Rebound hammer results.

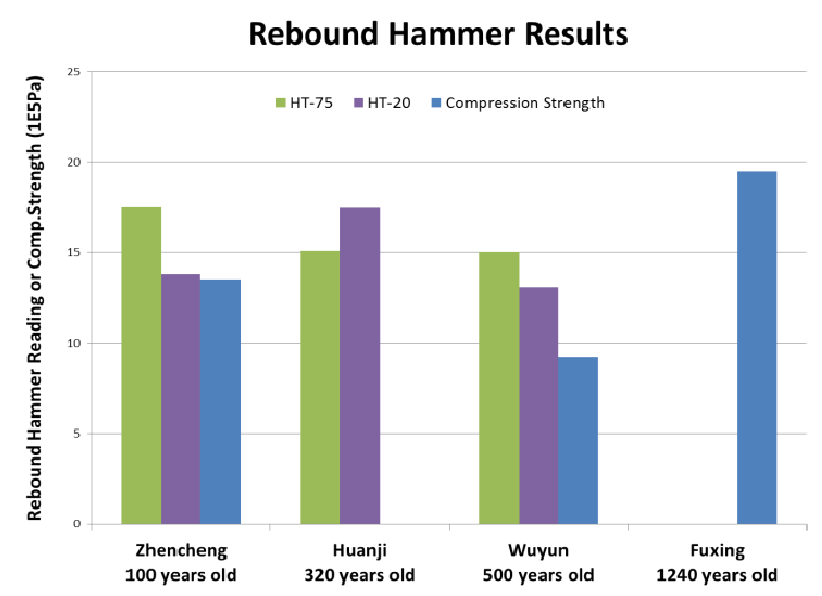

\subsection{Infrared Thermography Scanning Method}

Infrared thermography (IRT) is a viable NDE method potentially capable of scanning a large area of a structure being tested and detecting subsurface delaminations and debonding between the surface layer and the substrate. This technique is based on the principle that subsurface defects and delaminations affect the overall thermal conductivity of the material, leading to different rates of heat transfer through sound and defective regions and, thus, surface temperature differentials. In this study, a new portable IRT camera model InfraCAM SD Camera manufactured by FLIR Systems Inc. (North Billerica, MA, USA) was purchased and brought to China for field investigations.

The IRT camera was intended to perform a couple of functions upon verification of its usefulness during the field study. One function would be to identify the presence of a wall rib with reference to a wall without wall ribs. If successful, we would be able to quantify the spacing, pattern, size and total volume of wood or bamboo wall ribs used as reinforcement within a typical rammed earth wall. Unfortunately, it was found in the field that the IRT was not sensitive enough to detect the difference in the heat transfer rate between the walls with or without wall ribs. This is because the constituent materials to build a rammed wall, including earth, wood, bamboo, stone and others, are all natural materials. Under normal conditions, they are all thermally in equilibrium. The surface temperature difference between the walls with or without wall ribs is almost zero, especially when the wall ribs are embedded in a depth away from the wall surface and the wall has a thickness of 1.5 to 2 meters. Note that IRT is only able to identify defects under the subsurface (at a limited depth). For example, the IRT is indeed able to detect the wall rib, as shown in Figure 9, where a slightly dark shadow represents the wall rib, when the wall is around 12" in thickness with a crack in the vicinity. Due to the crack, wind effects and the shallow embedment of the rib in the wall, the temperature difference between the wall rib embedding area and its surrounding just meet the camera's sensitivity $\left(\sim 0.5^{\circ} \mathrm{C}\right)$.

Another expectation for the IRT camera was to try to see if it were able to detect the good or bad bond between the rammed earth and a wall rib. For the same reasons as stated above, the IRT camera was not sensitive enough to identify if the bond between the earth and wall rib was good or not. The 
temperature gradient in no way is big enough between those two conditions. During the field study, cold water was spread onto the rammed earth wall with the intention of signifying the difference in the heat transfer rate, but it was not effective.

Figure 9. IRT detecting shallow wall rib.

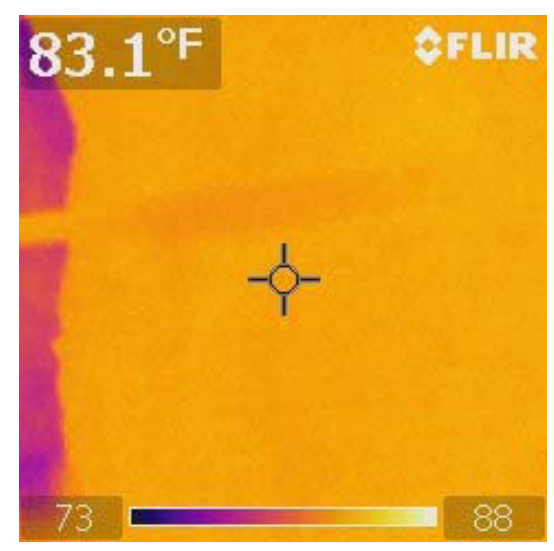

A third intention was to use the IRT camera to verify if there were any self-healing response of a crack-after-quake from Huanji Tulou, as discussed in depth in [8]. Unfortunately, it was found during the field study that Huanji Tulou was not reinforced by any wood strips, and the IRT was not found to be sensitive enough to identify the debond between a wall rib and rammed earth. Hence, no positive results were generated from the IRT camera.

\section{Structural Evaluation of Floor and Roof System}

When discussing the structural integrity of Hakka Tulou, attention should also be paid to the inner wooden structures. The inner wooden structures carry the loads that are experienced within the Tulou, as well as external loads, such as wind loads, and distribute these loads to both the rammed earth walls and the interior wooden columns.

\subsection{Full Scale Floor System Testing}

The floor system of a Tulou building consists of a number of columns, beams and floor panels (Figure 10). Each load carrying member is jointed to each other through a pinned connection. All horizontal beams are connected around the inner yard to make a circle. The focus of this set of load testing is to better understand how the floor member responds to an external load and how the load is distributed among the neighboring members.

The floor load testing was conducted between the third and fourth floor of Chengqi Tulou in the following steps: (1) identify representative structural units for the test; (2) mount a number of strain gages at appropriate locations; (3) connect strain gages to the multi-channel strain data acquisition; (4) apply load gradually and take readings from each channel under each loading; (5) download gradually and take readings; and (6) repeat the uploading and downloading tests three to four times.

The strain gage model BE120-50AA (resistance $120 \Omega$, length $50 \mathrm{~mm}$ ) was used and manufactured by Zhonghang Electronic Measuring Instruments Co. Ltd (ZEMIC). The strain data acquisition model DH3818 was used and manufactured by Donghua Testing Technology Co. Ltd. This acquisition 
system has 20 channels, a sensitivity of 1 microstrain ( $\mu \varepsilon$, parts per million) and zero floating of no more than 4 microstrain in $2 \mathrm{~h}$. The geometric dimensions of all the members were measured. The weights used were bags of metal clamps that were borrowed from a nearby restoration site (Wuyun Tulou). Each bag was $12.5 \mathrm{~kg}$, and a total 20 bags were used.

Figure 10. Load testing of floor system, member definition and strain gage locations.

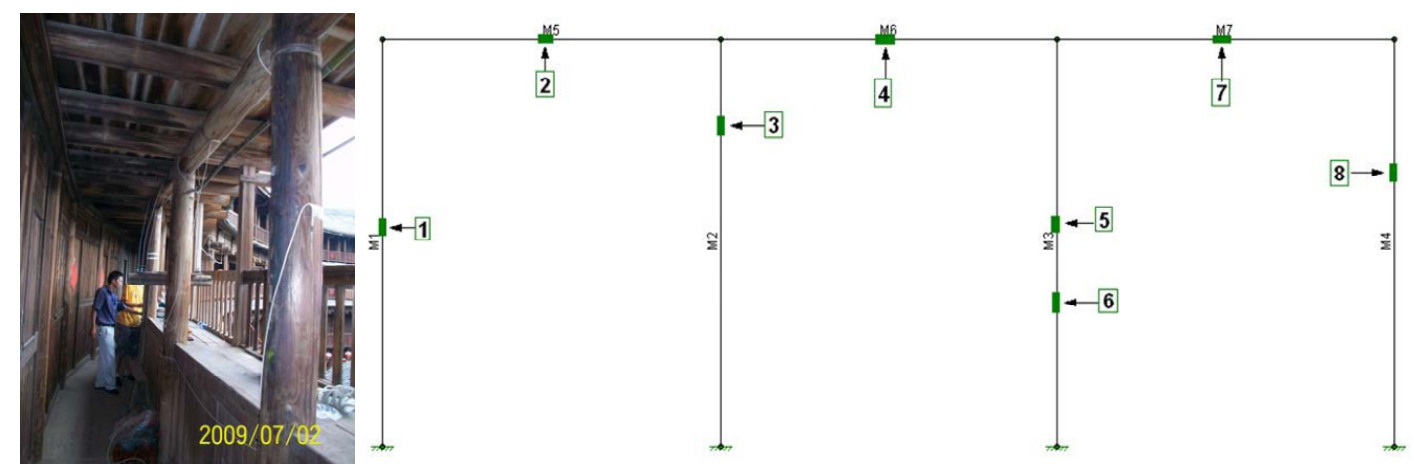

The floor system of Chengqi Tulou was tested by means of a two-point load of up to $250 \mathrm{~kg}$. The test section of the floor is shown in Figure 10 along with a schematic illustration, where each member is assigned with a number (M1 to M7) and strain gage locations are indicated. The load was applied onto Beam M6 between Column M2 and Column M3 as two equal concentrated loads symmetrically placed.

Load testing of such structures is also a form of nondestructive testing that allows us to evaluate the material and structural responses of a structure under external loads without damage to the structure itself. In order for a better understanding of the structural responses, finite element (FE) analyses were conducted to compare the strain gage data from the load test to the strain/stress values from an FE model. In this study, RISA 2D software was employed to model the responses of the floor and roof systems [9].

The strain data generated from the floor testing are graphically shown in Figure 11a, in terms of the strain gage locations and corresponding structural members, as defined in Figure 10. The strain was recorded as a function of loadings for each member. Each strain value at a given loading was an average of three measurements from three separate runs. The load applying member M6 (gage \#4) behaved as expected and gave a strain of 32 microstrains (parts per million) under maximal loading of $250 \mathrm{~kg}$. All other members had small strain values, except the vertical member M3 (gage \#5) that had unusually much higher values and gave a strain of 48 microstrains under $250 \mathrm{~kg}$.

\subsection{Full Scale Roof Truss Testing}

The roof truss structure is much more complicated than the floor system and is shown in Figure 12. The roof truss system consists of a group of horizontal members and vertical members, with each being connected to another through a pinned connection. The roof truss load testing was also conducted at Chengqi Tulou by means of a two-point loading of up to $250 \mathrm{~kg}$. The load was applied onto a horizontal beam with the largest span, while several vertical members supporting the roof beams were attached to this beam. Figure 12 shows a photo of the major sections of the roof truss structure being evaluated, while the entire roof truss structure is schematically illustrated, where each member is assigned with a number (M1 to M14), and strain gage locations are indicated with reference 
to the mounting member. More specifically, the load was applied onto Beam M10 between Columns M3 and M4.

Figure 11. Strain data from load testing, (a) floor system member strain data and (b) roof truss member strain data.

(a)

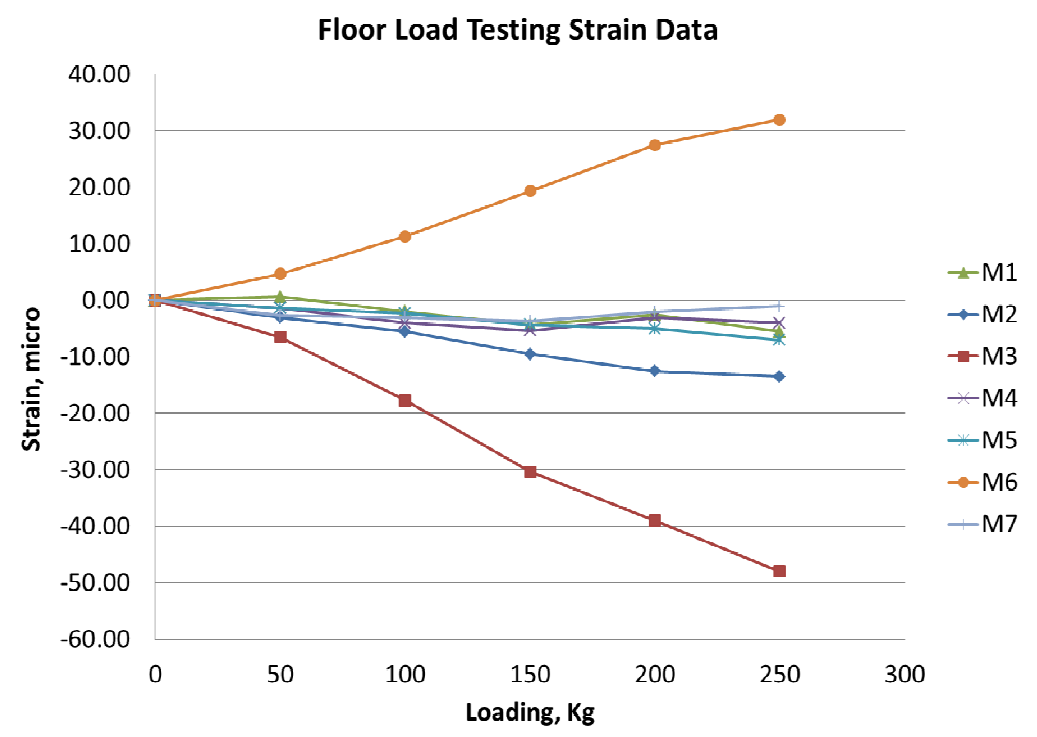

(b)

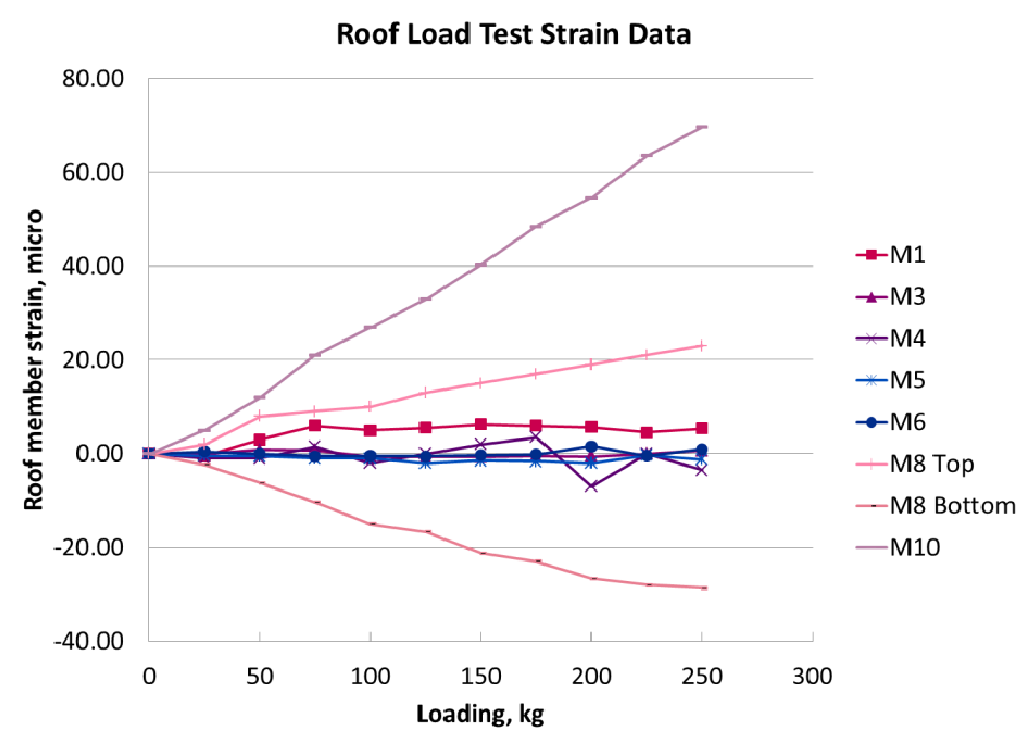

The strain data generated from the roof truss structure testing are graphically shown in Figure $11 \mathrm{~b}$, as per the strain gage locations and corresponding structural members defined in Figure 12. Similarly, the strain value was recorded as a function of loadings for each member mounted with a strain gage. Each strain value at a given loading was an average of three measurements from three separate runs, except that Member M4 (gage \#8) had only two sets of data to average, while the third set of data were mostly positive, resulting in an uncertain trend for Member M4. Such uncertain trend may be attributed to potential disturbance during testing or imperfect connection of wires to the strain gage. Note that the 
strain gages used were all $50 \mathrm{~mm}$ long gages to maximize the ability of detecting any small strains. All other members, except M4, behaved as expected. The load applying member M10 (gage \#4) resulted in 70 microstrains under a maximal loading of $250 \mathrm{~kg}$. For M8, the bottom side was subjected to compression (negative strain), and the strain values were closely matching those of the top tension side.

Figure 12. Load testing of Tulou roof truss, truss member definition and strain gage locations.

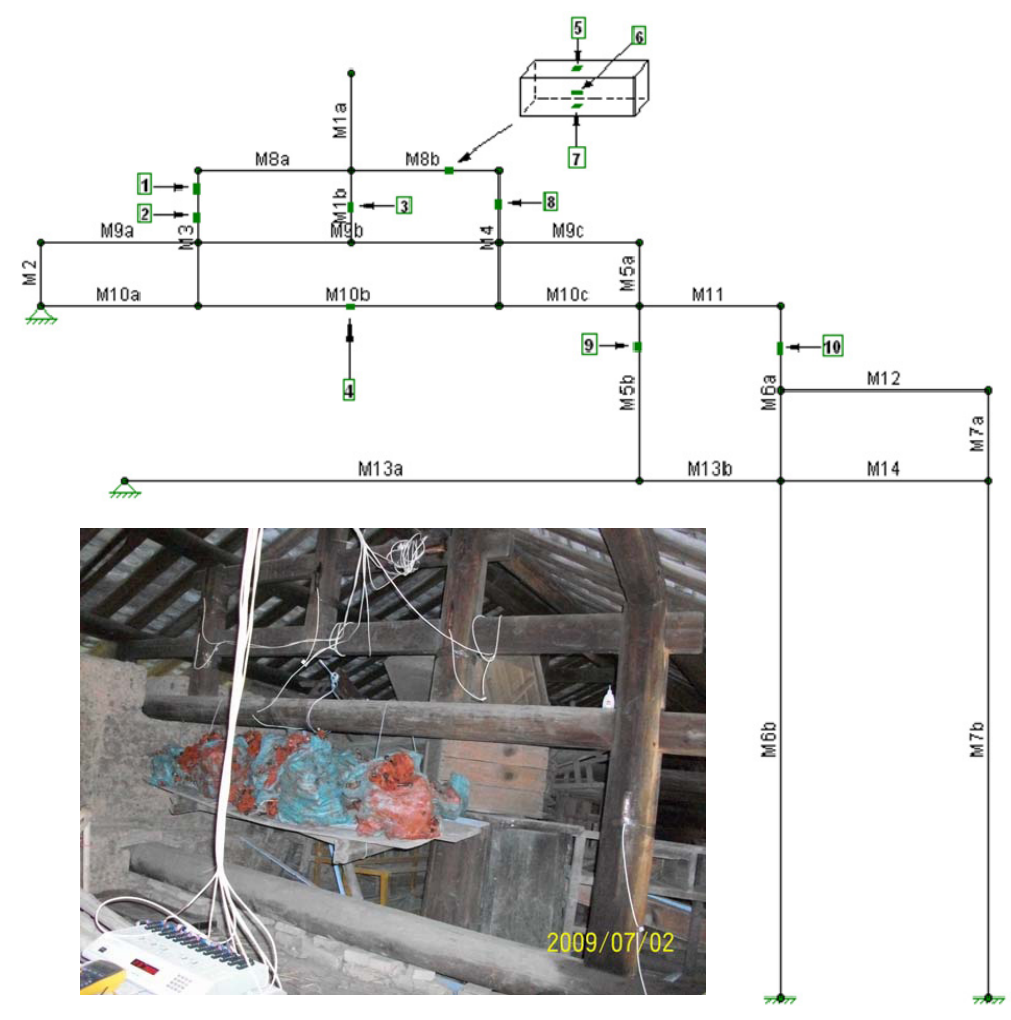

\subsection{Discussion on Load Sharing Effects of Floor and Roof Truss Systems}

The load testing of both the wooden floor and roof truss systems resulted in small strains in members, with the max strain about 32 microstrains from the floor test and about 70 microstrains from the roof test at a loading of $250 \mathrm{~kg}$. These field test results are listed in Table 2, Case (a). The access space available limited the application of additional loads. Caution was applied not to generate disturbance while conducting the field tests. Fortunately, strain responses from major loading members appeared to give meaningful trends. The results show that both the wooden roof truss and floor system are structurally sound even though the building is over 300 years old. From the FE analysis [9], for the floor system, a modulus of elasticity of $12.75 \mathrm{GPa}$ would match the field test results well (i.e., 32 microstrains on the load applying member), while for the roof truss, modulus of elasticity of $5.86 \mathrm{GPa}$ would match the roof load test results closely (70 microstrains on the load applying member). The FE results are listed in Table 2, Case (b). The difference in stiffness between the roof truss and floor system could be attributed to a number of factors.

Both the floor system and roof system were made of China-Fir [10]. China-Fir exemplifies excellent structural strength with a modulus of elasticity around $13.78 \mathrm{GPa}$, as well as a high decay resistance [11], which also helps explain how the Tulous are able to maintain their structural strength 
over such a long period of years. Both the floor and roof systems are found to be structurally sound. Another observation that can be made on the roof truss is that the intermittent vertical members, specifically M3 and M4, intercept the longer horizontal member of M10. By doing so, the moment has been dramatically reduced by cutting the effective length of the member. This shows that the Hakka people had a good understanding of force distribution within the wooden roof structure, as modern trusses are also similarly designed.

Table 2. Load sharing effects of floor and roof truss systems of Chengqi Tulou.

\begin{tabular}{|c|c|c|c|c|}
\hline & \multicolumn{2}{|c|}{ Floor System at $250 \mathrm{~kg}$} & \multicolumn{2}{|c|}{ Roof Truss at $250 \mathrm{~kg}$} \\
\hline & $\begin{array}{l}\text { Structure } \\
\text { Considered }\end{array}$ & $\begin{array}{c}\text { Strain at } \\
\text { Loading Beam } \\
(\mu \varepsilon) \\
\end{array}$ & $\begin{array}{c}\text { Structure } \\
\text { Considered }\end{array}$ & $\begin{array}{c}\text { Strain at } \\
\text { Loading Beam } \\
(\mu \varepsilon) \\
\end{array}$ \\
\hline $\begin{array}{l}\text { a) Field Load Test } \\
\text { Data, Pinned } \\
\text { Connection for All } \\
\text { Members }\end{array}$ & $p_{i}^{p_{i}} p_{i}$ & 32 & & 70 \\
\hline $\begin{array}{l}\text { b) RISA 2D Model } \\
\text { Data, Pinned } \\
\text { Connection for All } \\
\text { Members }\end{array}$ & $i_{i}^{p / p / 2}$ & $\begin{array}{c}32 \\
(E=12.75 \text { GPa })\end{array}$ & & $\begin{array}{c}70 \\
(E=5.86 \text { GPa })\end{array}$ \\
\hline $\begin{array}{l}\text { c) Simple Beam, Two } \\
\text { Equal Concentrated } \\
\text { Loads Symmetrically } \\
\text { Placed }\end{array}$ & $\rightarrow \rightarrow$ & $\begin{array}{c}68 \\
(E=12.75 \mathrm{GPa})\end{array}$ & & $\begin{array}{c}311 \\
(\mathrm{E}=5.86 \mathrm{GPa})\end{array}$ \\
\hline $\begin{array}{l}\text { d) Beam Fixed at Both } \\
\text { Ends, Two Equal } \\
\text { Concentrated Loads } \\
\text { Symmetrically Placed }\end{array}$ & 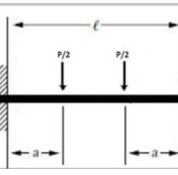 & $\begin{array}{c}17 \\
(E=12.75 \text { GPa })\end{array}$ & 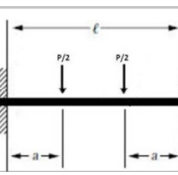 & $\begin{array}{c}101 \\
(E=5.86 \mathrm{GPa})\end{array}$ \\
\hline
\end{tabular}

To quantify how the floor and roof truss members respond to an external load and how the load is distributed among the neighboring members, we can further compare the strain data from each load testing with those from two extreme cases with well-defined boundary conditions, as represented by Cases (c) and (d) in Table 2.

For a simply supported beam with two equal concentrated loads symmetrically placed, as shown in Case (c) of Table 2, the maximum strain can be determined by the following equation [12]:

$$
\varepsilon=\frac{16 P a}{\pi D^{3} E}
$$

where $\varepsilon$ is the strain, $\mathrm{P}$ is the total load, a is the distance of the loading point away from the support, D is the diameter and $\mathrm{E}$ is the modulus of elasticity.

For a beam fixed at both ends, with two equal concentrated loads symmetrically placed, as shown in Case (d) of Table 2, the maximal strain can be determined by the following equation [12]: 


$$
\varepsilon=\left(\frac{a}{l}\right) \frac{16 P a}{\pi D^{3} E}
$$

where 1 is the length of the beam, $\varepsilon$ is the strain, $\mathrm{P}$ is the total load, a is the distance of the loading point away from the support, $\mathrm{D}$ is the diameter and $\mathrm{E}$ is the modulus of elasticity.

For the floor test, $1=2.03 \mathrm{~m}, \mathrm{a}=0.51 \mathrm{~m}, \mathrm{D}=0.19 \mathrm{~m}, \mathrm{P}=250 \mathrm{~kg}, \mathrm{E}=12.75 \mathrm{GPa}$. As per from Case (b) of Table 2, Equations 1 and 2 give a maximum strain of $68 \mu \varepsilon$ for a simple support beam and $17 \mu \varepsilon$ for a fixed beam, respectively; For the roof truss test, $1=2.90 \mathrm{~m}, \mathrm{a}=0.94 \mathrm{~m}, \mathrm{D}=0.19 \mathrm{~m}, \mathrm{P}=250 \mathrm{~kg}$, $\mathrm{E}=5.86 \mathrm{GPa}$. As per from Case (b) of Table 2, Equations 1 and 2 give a maximum strain of $311 \mu \varepsilon$ for a simple support beam and $101 \mu \varepsilon$ for a fixed beam, respectively. All these values are listed in Table 2 and compared with the strain data from field load tests.

Therefore, as presented in Table 2, it is noted that for the floor system load test, its loading scenario can be idealized through a simple beam with a fixed end model as opposed to a simple beam bending model. More specifically, with the simple beam case being a " 0 " moment at the supports and showing 68 microstrain, and a fixed beam case being a "100\%" moment constraint at the supports and giving 17 microstrain, the structural redistribution of moment because of the floor system will be a value of "71\%", which is computed from a field measurement value of 32 microstrain. This result demonstrates that the jointed neighboring members have a high load-sharing effect in a manner similar to a fixed beam. Similarly, for the roof truss load test, with the simple beam case being a " 0 " moment at the supports, but resulting in 311 microstrain, and the fixed beam case being a "100\%" moment constraint at the supports, while yielding 101 microstrain, the field strain measurement further illustrates that the roof truss system being tested is providing extra stiffness, resulting in a microstrain value of 70 only. This means that all the surrounding horizontal and vertical members connected to the load carrying beam have acted in partial unison and restrained the load carrying beam such that the boundary conditions surpass those of a fixed beam.

\section{Thermal Comfort Analysis of Living in Hakka Tulou}

The Fujian Province lies at the end of the temperate zone closest to the equator, meaning that the region has four seasons throughout the year. The winters tend to be very mild while the summers are fairly hot. The field study would like to find out how Hakka families live within the walls of Hakka Tulou in comfort both in summer and winter.

In this case of thermal analysis, the heat transfer is from conduction, which means that heat energy is transferred from one part of a material to another until temperature equilibrium is reached. Two important thermo-physical properties of a material have to be considered that can control the process of conduction and, in turn, control the thermal comfort of any structure. These properties are known as the thermal resistivity and thermal mass of a material. The thermal resistance of a material is the ability of a material to resist heat flow, meaning that the higher the thermal resistance of a material, the more the material will resist temperature change with respect to its surrounding temperature. Thermal mass, meanwhile, is the ability of a material to absorb and release heat in an attempt to reach a thermal equilibrium with its surrounding area [13]. It is well known that materials with high thermal mass have relatively low thermal resistivity and, thus, are not good insulators. Materials that typically have high 
thermal mass, and thus absorb a lot of heat energy in order to change temperature, are high density materials, such as concrete, brick and, in this case, rammed earth.

In order to illustrate how effectively the use of high thermal mass has been implemented in the Hakka Tulou, temperature and humidity data were recorded. On 1 July 2009, temperature and humidity readings were recorded from time to time at Chengqi Tulou and are shown in Tables 3 and 4, respectively. Seven-day period temperature and humidity data obtained using Data Loggers at Chengqi Tulou from 29 June to 6 July 2009 were presented and analyzed by Ueda [14].

Table 3 shows temperatures recorded at different locations of the Chengqi Tulou, i.e., outside the Tulou, the outer and inner rammed earth wall surfaces, inside an interior room, etc. As can be seen from Table 3, the hottest that the outer surface of the rammed earth wall ever reached was $112^{\circ} \mathrm{F}$, with a temperature profile inside and outside the Tulou shown in Figure 13. Since this was the most extreme temperature difference, this set of temperatures at 15:20 was used to calculate the thermal resistivity in situ, giving a thermal resistivity of $1.0986 \mathrm{~m} . \mathrm{K} / \mathrm{W}$ [9].

Table 3. Temperature data of Chengqi Tulou (Field collected 1 July 2009).

\begin{tabular}{lccccccc}
\hline & \multicolumn{6}{c}{ Temperature data (F) at different locations of thermocouple } \\
\cline { 2 - 8 } Time & $\begin{array}{l}\text { Court } \\
\text { yard }\end{array}$ & $\begin{array}{l}\text { Inside } \\
\text { room }\end{array}$ & $\begin{array}{l}\text { Inner wall } \\
\text { surface }\end{array}$ & $\begin{array}{l}\text { Inside inner } \\
\text { wall }\end{array}$ & $\begin{array}{l}\text { Inside } \\
\text { outer wall }\end{array}$ & $\begin{array}{l}\text { Outer wall } \\
\text { surface }\end{array}$ & Outer yard \\
\hline $10: 50$ & 80.2 & 80.2 & 81 & 79.9 & 81.9 & 88 & 82.9 \\
$12: 00$ & 81.5 & 79.7 & 81 & 79.9 & 82.2 & 89 & 84 \\
$13: 30$ & 82.4 & 79.5 & 83 & 79.9 & 82.9 & 95 & 89.6 \\
$15: 20$ & 82.9 & 79.5 & 81 & 80.1 & 84.7 & 112 & 96.1 \\
$18: 00$ & 82.6 & 79.7 & 80 & 80.1 & 90.7 & 101 & 96.6 \\
\hline
\end{tabular}

Figure 13. Chengqi Tulou temperature profile.

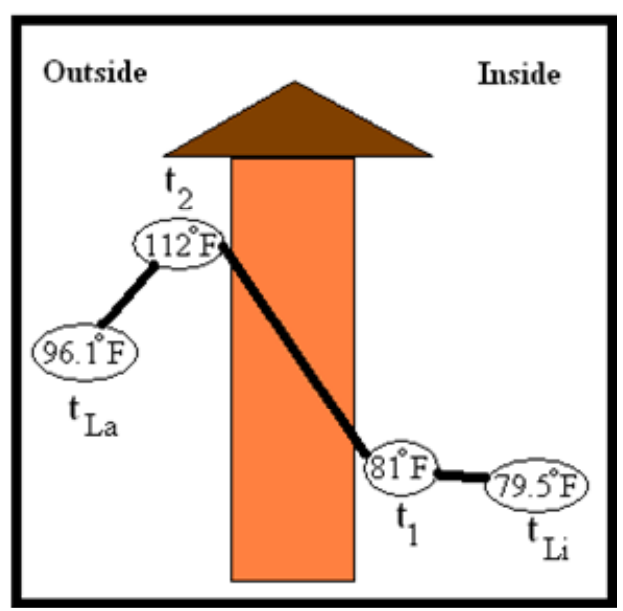

More commonly, materials are rated on their thermal resistance, which is denoted as the " $R$ " value. The " $R$ " value represents the ability of a material per unit thickness to resist heat flow. The higher the " $R$ " value, the more the material is resistant to heat per unit thickness. To calculate the ' $R$ ' value of the entire rammed earth wall, we use the thickness of the rammed earth wall at the Chengqi Tulou of 1.8 meters and multiply it by the thermal resistivity, resulting in a " $\mathrm{R}$ " value of $1.96 \mathrm{~m}^{2} . \mathrm{K} / \mathrm{W}$. This value is far better than the reported rammed earth $\mathrm{R}$ values of an average of $0.4 \mathrm{~m}^{2} . \mathrm{K} / \mathrm{W}$ [15]. As per the 
building code of Australia (ABCB, 2010), all external walls of a residential building must have a minimum $R$ value of $2.8 \mathrm{~m}^{2} \mathrm{~K} / \mathrm{W}[15]$.

Hakka Tulou have no insulation in their rammed earth walls and instead rely on the high thermal mass that rammed earth provides. Materials that have a high density, such as concrete and rammed earth, require more heat energy to change their temperature, while materials with low density, such as wood, do not need a lot of heat energy in order to change temperatures. The thermal mass finds a good application in the case of Hakka rammed earth buildings, where the internal temperatures of a structure are kept stable when compared to varying outside temperatures [13]. More specifically, during the hot summer season, the massive rammed earth wall with a high thermal mass would absorb the heat from the outside, while keeping the interior cool during the day. At night, the wall would release the heat to keep the interior temperature stable when compared to the colder night temperatures outside. During the winter, the rammed earth wall would be heated by direct sunlight in order to release heat and keep the interior temperatures at a comfortable level. These thermal comfort benefits have also been observed in cave dwellings [16].

Table 4 humidity data also reveal an interesting observation. Even though the outside relative humidity varied from $71 \%$ to $46 \%$, the humidity inside the room remained almost constant at $79 \%$. The rammed earth wall regulates the room temperature and humidity satisfactorily. Seven-day period climate data [14] clearly showed that while temperature or humidity fluctuated outside, the interior temperature or humidity remained constant at a comfortable level throughout the entire week. The thermal comfort zone of living in the Hakka building is achieved due to the effective use of thermal mass from the rammed earth walls.

Table 4. Humidity data of Chengqi Tulou (field collected 1 July 2009).

\begin{tabular}{cccccc}
\hline & \multicolumn{5}{c}{ Location of humidity sensor } \\
\cline { 2 - 6 } Time & $\begin{array}{c}\text { Court } \\
\text { yard }\end{array}$ & $\begin{array}{c}\text { Inside } \\
\text { room }\end{array}$ & $\begin{array}{c}\text { Inside } \\
\text { inner wall }\end{array}$ & $\begin{array}{c}\text { Inside outer } \\
\text { wall }\end{array}$ & Outer yard \\
\hline 10:50 & 74 & 78 & 82 & 66 & 71 \\
$12: 00$ & 74 & 80 & 82 & 65 & 69 \\
$13: 30$ & 69 & 79 & 82 & 49 & 60 \\
$15: 20$ & 69 & 79 & 81 & 32 & 53 \\
$18: 00$ & 69 & 79 & 81 & 38 & 46 \\
\hline
\end{tabular}

\section{Conclusions}

Through this study, we have investigated five in-service Hakka rammed earth structures, i.e., Fujian Tulou of China, in terms of their material and structural responses under thermal and mechanical loads. This paper is the first paper of the two papers presenting the findings of the study with emphasis on the observations and discussions from the field nondestructive evaluations, including infrared thermography, rebound hammer, ultrasonic testing, thermocouples and load tests on roof trusses and floors. The results show that NDE techniques, such as ultrasonic and rebound hammer, appeared to be able to quantitatively compare the strength of rammed earth walls, while infrared thermography was not found to be sensitive enough to detect the presence of wall ribs. The full-scale load testing result and structural analyses conclude that both the floor and roof truss systems are structurally sound, and 
the jointed neighboring members have a high load-sharing effect with the load-carrying beam. The Hakka people found ways to live in thermal comfort without the need of mechanical heating in winter or cooling in summer due to their effective use of rammed earth construction. This was done without the use of insulation, which would help better maintain heat within the structure during the winter seasons. Modern construction can simulate the Hakka construction techniques and makes rammed earth construction a viable building material option of the future.

\section{Acknowledgments}

This study was supported by a research grant of US-NSF (CMMI \#0908199). The PI (Ruifeng Liang) would like to acknowledge the support and assistance, from Yongding County Government of Fujian Province of China during the field study. He would also like to thank Jorg Ostrowski of ASH for reviewing the field study plan and comments prior to the field trip; Minoru Ueda of MU Design for collecting temperature and humidity data of Chengqi Tulou; and Udaya Halabe of WVU for advising on NDT techniques.

Ruifeng Liang would also like to thank the following individuals for their help and assistance during the field study from 15 June to 15 July 2009: Chen Guoping, Shanghang County Official; Chen Qinghai, Nanxi Tulou Administration of Yongding County; Jiang Youyu, Owner of Chengqi Tulou and Wuyun Tulou; Kong Meichang, Owner of Fuxing Tulou; Lai Fuqun, Gaobei Tulou Administration of Yongding County; Li Xiaoping, Longyan City Official; Li Zhibing, Gaotou Town Official; Liang Jianxin, Longyan City Official; Liao Qingtang, Hongkeng Tulou Administration of Yongding County; Liao Minjuan, Hulei Town Official; Lin Shanghua, Hongkeng Tulou Administration of Yongding County; Lin Shangshang, Owner of Zhencheng Tulou; Lu Meiqun, Tour Guide; Su Chongbiao and Su Xianming, Nanxi Village; Xie Jihong, Rental Van Driver; Xu Xiaojian, Longyan City Police Officer; Yu Dehui, Yongdong Official; Zhang Yufeng, Chengqi Tulou Resident; Zhang Zhaoting and Zheng Xincai, Yongding County Officials.

\section{Conflict of Interest}

The authors declare no conflict of interest.

\section{References and Notes}

1. Jaquin, P.A. Historic Rammed Earth. Available online: http://www.historicrammedearth.co.uk/ (accessed on 10 November 2008).

2. NAREBA. North American Rammed Earth Builders Association. Available online: http://www.nareba.org/about.html (accessed on 10 November 2008).

3. Collins, H. Desert Living Center in Las Vegas Teaches Sustainability. Available online: http://www.govtech.com/technology/Desert-Living-Center-in-Las-Vegas-Teaches-Sustainability. html (accessed on 17 January 2013).

4. Aaberg-Jørgensen, J. The Construction of Clan Homes in Fujian. Available online: http://www.chinadwelling.dk/ (accessed on 10 November 2008) 
5. Ostrowski, J.; Ostrowski, H.; Li, X.Y.; Ueda, M. Hakka Eco-Village Study Tour Report, Internal Report; ASH-Inc.: Calgary, AB, Canada, 2007.

6. Liang, R.; Hota, G. Hakka Tulou and Science. In Hakka Tulou Forum 2009: Lessons to Be Learned, Past, Present and Future; Xiamen University, Xiamen, China, 2009.

7. Halabe, U.B.; Petro, S.H.; Hota, G. NDE Methods for Highway Bridge Superstructures; Report No. 95-215; West Virginia University Constructed Facilities Center: Morgantown, WV, USA, 1995.

8. Liang, R.; Stanislawski, D.; Hota, G. Structural Responses of Hakka Rammed Earth Buildings under Earthquake Loads. In Proceedings of International Workshop on Rammed Earth Materials and Sustainable Structures, Xiamen University, Xiamen, China, 28-31 October 2011; Southeast University Press: Xiamen, China, 2011.

9. Stanislawski, D. Mechanical Response and Finite Element Modeling of Hakka Tulou Rammed Earth Structures. MSCE Thesis, West Virginia University, Morgantown, WV, USA, 2011.

10. Wang, F. A History of the Tulou Buildings; Haifeng Publishing House: Fuzhou, China, 2008.

11. Green, D.W.; Winandy, J.E.; Kretschmann, D.E. Mechanical properties of wood. In Wood Handbook-Wood as An Engineering Material; US Department of Agriculture Forest Products Laboratory: Madison, WI, USA, 1999; Chapter 4.

12. PCI. Design Handbook Precast \& Prestress Concrete, 4th ed.; Precast/Prestressed Concrete Institute: Chicago, CA, USA, 1992.

13. Reardon, C.; McGee, C.; Milne, G. Your Home Technical Manual, 4th ed.; Australian Government Department of Climate Change and Energy Efficiency: Canberra, Australia, 2010. Available online: http://www.yourhome.gov.au/technical/index.html (accessed on 24 January 2011).

14. Ueda, M. A preliminary environmental assessment for the preservation and restoration of Fujian Hakka Tulou complexes. Sustainability 2012, 4, 2803-2817.

15. Ciancio, D. Use of Rammed Earth in Aboriginal Remote Communities of Western Australia: A Case Study on Sustainability and Thermal Properties. In Proceedings of Int. Workshop on Rammed Earth Materials and Sustainable Structures; Xiamen University, Xiamen, China, 28-31 October 2011; Southeast University Press: Xiamen, China, 2011.

16. Watanabe, T. Study of Energy Consumption and Indoor Environment Problems of Residential Buildings in China by Research Committee of Architectural Institute of Japan. Available online: http: //news-sv.aij.or.jp/t300/HP/English3.pdf (accessed on 10 November 2008).

(C) 2013 by the authors; licensee MDPI, Basel, Switzerland. This article is an open access article distributed under the terms and conditions of the Creative Commons Attribution license (http://creativecommons.org/licenses/by/3.0/). 